\title{
Conhecer trajetórias de estudantes negros(as) do ensino médio para transformar histórias de vida
}

\author{
Natalino Neves da Silva ${ }^{1}$ \\ Helenilce Aparecida da Costa Bernardo ${ }^{2}$
}

\section{RESUMO}

Este artigo resulta de uma pesquisa no ensino médio que fez parte do projeto Núcleo de Estudos Africanos, Afro-brasileiros e da Diáspora (UBUNTU/NUPEAAs) da Secretaria de Estado de Educação de Minas Gerais (SEE-MG), com a participação de treze estudantes pesquisadores(as) em uma escola pública localizada em Poços de Caldas, Minas Gerais. O problema proposto consistiu em entender como jovens estudantes negros(as) lidam com o processo de construção identitário étnico-racial. Foram aplicados 950 questionários com o intuito de mapear o perfil estudantil. Além disso, foram feitas ainda entrevistas semiestruturadas por meio de quatro grupos focais. Os resultados alcançados apontam que a constituição identitária étnico-racial dos(as) jovens negros(as) se manifesta em meio à vivência de uma trajetória marcada pelo racismo, preconceito e discriminação racial. Essa constatação implica a necessidade de investir em práticas educativas voltadas para a promoção da igualdade étnico-racial.

PALAVRAS-CHAVE: Ensino Médio. Educação das Relações Étnicoraciais.

Know the trajectories of black high school students to transform life stories

\section{ABSTRACT}

\footnotetext{
${ }^{1}$ Doutor em Educação. Universidade Federal de Alfenas, Alfenas, Minas Gerais, Brasil. https://orcid.org/0000-00021746-8713.professornatalino@gmail.com.

${ }^{2}$ Licenciada em História. Escola Estadual Padrão, Poços de Caldas, Minas Gerais, Brasil. https://orcid.org/00000002-6411-7756.helebernardo@hotmail.com.
} 
This article is the result of a research that was part of the Nucleus of African, Afro-Brazilian and Diaspora (UBUNTU/NUPEAAs) project of the Minas Gerais State Department of Education (SEE-MG) thirteen student researchers participated in a public school located in Poços de Caldas, Minas Gerais. The proposed problem was to understand how young black students deal with the process of ethnic-racial identity construction. 950 questionnaires were applied in order to map the student profile. Semi-structured interviews were conducted through 04 focus groups. The results show that the ethnic-racial identity constitution of young black people is in the midst of living a trajectory marked by racism, prejudice and racial discrimination. This worrying finding implies the need to invest in educational practices aimed at promoting ethnic and racial equality.

KEYWORDS: High school. Education of Ethnic-Racial Relations. Scientific research

\section{Introdução}

Este artigo resulta de uma pesquisa no ensino médio ${ }^{3}$, que fez parte do projeto Núcleo de Estudos Africanos, Afro-brasileiros e da Diáspora (UBUNTU/NUPEAAs) da Secretaria de Estado de Educação de Minas Gerais (SEE-MG) ${ }^{4}$, realizada com 13 estudantes $^{5}$ em uma escola pública localizada em Poços de Caldas, Minas Gerais, durante o ano de 2018.

O projeto UBUNTU/NUPEAAs ${ }^{6}$ visou implementar o ensino de História e Cultura Afro-brasileira e Africana, conforme previsto na Lei $\mathrm{n}^{\circ}$.

\footnotetext{
${ }^{3}$ A Fundação de Amparo à Pesquisa do Estado de Minas Gerais (FAPEMIG) financiou a realização deste estudo. ${ }^{4} \mathrm{O}$ projeto UBUNTU/NUPEAAs faz parte das ações da Campanha "Afroconsciência: com essa história, a escola tem tudo a ver", lançada pela Secretaria de Estado de Educação de Minas Gerais, em 2015. Teve como objetivo promover a Educação para as Relações Étnico-Raciais no ensino médio das escolas estaduais do Estado de MG.

${ }^{5}$ A IC contou com a participação voluntária dos seguintes jovens pesquisadores(as): Ana Beatriz Campanelli, Victor Augusto Capellari, Isac Alexandre de Paula Gonçalves, Lavinia Pereira Lellis, Letícia Ferreira Marcos, Helen Victória de Paula, Nicole Cristina dos Santos, Larissa Morais Del Sarto, Ellen Cristina Ferreira da Silva, Janine Idineide da Silva, Stephany Mainny M. Xavier Silva, Victoria Gonçalves da Costa e Silva, Thais Alves de Souza.

${ }^{6}$ A Fundação de Amparo à Pesquisa do Estado de Minas Gerais (FAPEMIG), o Instituto Unibanco, a Organização Não Governamental (ONG) Ação Educativa e diferentes Instituições de Ensino Superior (IES) foram os principais interlocutores para a execução deste projeto.
} 
10.639/037, no Parecer CNE/CP no. 003/2004, na Resolução CNE/CP nº. 001/2004, que institui Diretrizes Curriculares Nacionais para a Educação das Relações Étnico-Raciais e para o ensino da História e Cultura Afrobrasileira e Africana (DCNERER).

A proposta inicial de pesquisa consistia em conhecer trajetórias de estudantes negros e negras da escolaridade média. A proposta foi submetida e aprovada por meio de Edital de Seleção, no qual seria necessário abordar perspectivas analíticas políticas e socioculturais da história africana e afrobrasileira ${ }^{8}$.

O pioneirismo do projeto UBUNTU/NUPEAAs, como uma política de ação afirmativa voltada para promover a igualdade racial na Educação Básica, foi formulado e constituído nos anos de 2015 e 2017. O prazo de duração dos projetos selecionados seria de dez meses durante o ano de 2018 (CUNHA et. all, 2018).

O estudo teve início em março e foi concluído em dezembro do referido ano. A realização do projeto envolveu discentes dos três turnos. Cabe ressaltar que a efetivação do estudo só foi possível devido ao apoio incondicional recebido por parte da gestão escolar no âmbito de criação do NUPEAAs. Os demais profissionais de educação foram bastante receptivos em relação ao desenvolvimento do projeto. Muitos(as) deles(as) se envolveram nas ações propostas pelo Núcleo.

O problema central proposto objetivou entender como jovens estudantes negros(as) ${ }^{9}$ lidam com o processo de construção identitário étnico-racial ${ }^{10}$ tanto na escola quanto fora dela. Essa indagação é fruto da

\footnotetext{
${ }^{7}$ A Lei $n^{\circ} 10.639$ alterou a Lei de Diretrizes e Bases da Educação Nacional (LDBEN 9.394/96), que passou a vigorar acrescida dos artigos: Art. 26-A, Art. 79-A (Vetado) e o Art. 79-B, a qual prevê a obrigatoriedade do ensino sobre a História e Cultura Afro-brasileira e Africana na educação básica ofertada nos estabelecimentos de ensino públicos e particulares. Essa Lei foi alterada em 2008 pela Lei no . 11.645, passando a incluir a História e Cultura dos Povos Indígenas Brasileiros. Neste artigo, abordamos a perspectiva da educação das relações étnico-raciais.

${ }^{8}$ As perspectivas analíticas para a submissão do projeto foram: Cultura, memória e ancestralidade; Construção e fortalecimento das identidades afrodescendentes na contemporaneidade; Participação social, comunitária e política de combate ao racismo e à discriminação racial; Africanidades, Ciências, Engenharias e Tecnologias.

${ }^{9}$ Entende-se negro como uma categoria analítica constituída por pessoas que se autodeclaram como pretas e pardas, conforme levantamento censitário realizado pelo Instituto Brasileiro de Geografia e Estatística (IBGE).

10 O Núcleo contou em sua composição com onze estudantes autodeclarados(as) negros(as) e dois que se autodeclaram brancos(as), com renda familiar entre 1 e 3 salários mínimos, na faixa etária entre 16 e 18 anos e residentes em bairros próximos à escola.
} 
necessidade de conhecer melhor a realidade dos novos sujeitos inseridos na escolaridade média por meio do enfoque das relações étnico-raciais.

A Escola Estadual Beatriz Nascimento ${ }^{11}$ está localizada na periferia do centro urbano da cidade de Poços de Caldas, cuja maior parte da população estudantil atendida é de negros(as). A importância de entender esse grupo por meio da pertença étnico-racial está relacionada a tomar conhecimento de trajetórias juvenis perpassadas por desigualdades sociorraciais $^{12}$ e escolares, conforme apontam pesquisas realizadas na área, há vários anos (ARAÚJO, 2014, CARVALHO; CASTRO, 2017, SILVA; HASENBALG, 2000).

A esse respeito, as informações da Pesquisa Nacional por Amostra de Domicílio Contínua (PNAD-Contínua) 2018, divulgadas pelo IBGE, revelam a persistência de desigualdades por cor/raça, gênero e região. Uma análise dos dados mostra que a frequência mínima de pessoas de 15 a 17 anos, no ensino médio, autodeclaradas brancas, foi $76,5 \%$, enquanto para as pessoas autodeclaradas pretas ou pardas, 64,9\%. O percentual comparativo entre mulheres e homens, compreendidos por essa faixa etária que frequentavam e/ou concluintes desse nível de ensino, foi 74,4\% e 64,5\%, respectivamente. No que concerne à frequência de jovens por região, constatou-se que, entre 2017 e 2018, as regiões Norte e Nordeste apresentaram as menores frequências, de $61,9 \%$ e $61,3 \%$. Nas demais regiões do país, esse índice foi maior de $70 \%$.

Nesse sentido, a compreensão desse quadro de exclusão sociorracial foi desvelado pelos próprios sujeitos atingidos por essa estatística. Consequentemente, jovens negros(as) e brancos(as) participantes da IC foram adquirindo determinado nível de consciência étnico-racial acerca das

\footnotetext{
${ }^{11}$ No sentido de preservar a identificação da instituição, empregamos o nome de uma importante intelectual negra brasileira.

12 Raça é aqui entendida como uma construção científica, sociocultural e política. Para Guimarães (2003, p.96), a sociologia deve compreendê-la como "discursos sobre as origens de um grupo, que usam termos que remetem à transmissão de traços fisionômicos, qualidades morais, intelectuais, psicológicas, etc., pelo sangue" os quais geralmente dizem respeito às identidades sociais coletivas.
} 
desigualdades sociorraciais que afetam não só diretamente a eles(as), como também toda a sociedade brasileira.

Pesquisar trajetórias estudantis possibilitou uma maior compreensão a respeito de como esses preocupantes dados incidem sobre a realidade social, sobretudo de jovens negros(as). Além disso, contribuiu para identificar e desnaturalizar os modos pelos quais as desigualdades sociorraciais são produzidas e reproduzidas na/pela escola.

Sendo assim, diferentes procedimentos metodológicos foram utilizados com vistas a atingir o objetivo geral de realização da pesquisa. Inicialmente, nos três turnos, foram aplicados 950 (novecentos e cinquenta) questionários, com questões fechadas sobre a autodeclaração étnico-racial estudantil e questões abertas a respeito da percepção do preconceito e da discriminação racial tanto na instituição escolar quanto fora dela.

Do mapeamento realizado constatou a presença significativa de estudantes negros(as) inseridos nos diferentes turnos, conforme podemos constatar na tabela 1 .

TABELA 1: Perfil Étnico-Racial Estudantil13

\begin{tabular}{|c|c|c|}
\hline \multirow{6}{*}{ Matutino } & Autodeclaração Cor/Raça & Quantidade \\
\hline & Negro & 207 \\
\hline & Branco & 160 \\
\hline & Amarelo & 1 \\
\hline & Indígena & 23 \\
\hline & & Total: 391 \\
\hline \multirow{6}{*}{ Vespertino } & Autodeclaração Cor/Raça & Quantidade \\
\hline & Negro & 177 \\
\hline & Branco & 104 \\
\hline & Amarelo & 3 \\
\hline & Indígena & 9 \\
\hline & & Total: 293 \\
\hline & Autodeclaração Cor/Raça & Quantidade \\
\hline
\end{tabular}

\footnotetext{
13 Devido a rejeição estudantil em se autodeclarar "preto", conforme categoria censitária utilizada pelo IBGE, optamos por trabalhar com a categoria analítica "negro" (pretos e pardos) no sentido de corresponder com o sentimento de identificação étnico-racial desses sujeitos.
} 


\begin{tabular}{l|l|r}
\hline \multirow{4}{*}{ Noturno } & Negro & 165 \\
\cline { 2 - 3 } & Branco & 92 \\
\cline { 2 - 3 } & Amarelo & 4 \\
\cline { 2 - 3 } & Indígena & 5 \\
\cline { 2 - 3 } & & Total: 266 \\
\hline
\end{tabular}

Fonte: Pesquisa realizada pelos autores.

$\mathrm{Na}$ etapa seguinte, foi realizada uma assembleia contando com a participação da comunidade escolar, com o intuito de apresentar, discutir e realizar um diagnóstico da qualidade das relações étnico-raciais na escola. Para tal, o trabalho foi fundamentado por meio dos Indicadores de Qualidade na Educação: relações raciais na escola, tendo em vista que:

Este material foi elaborado para apoiar a escola no diagnóstico dos seus problemas e na busca de soluções para a melhoria da qualidade educacional, tendo como focos a superação do racismo no cotidiano escolar e a implementação da Lei no . 10.639/03. (...) Os Indicadores de Qualidade na Educação: Relações Raciais na Escola são compostos por sete dimensões: relacionamento e atitudes; currículo e prática pedagógica; recursos e materiais didáticos; acompanhamento, permanência e sucesso; a atuação dos/das profissionais de educação; gestão democrática; para além da escola (CARREIRA; SOUZA, 2013, p. 18).

A utilização dos Indiques como instrumento de avaliação diagnóstica da qualidade das relações étnico-raciais na escola contribuiu para ampliar a atuação de realização do estudo incialmente pensada, oportunizando um maior envolvimento da comunidade escolar nas ações desenvolvidas pelo Núcleo.

Um grupo guardião ${ }^{14}$, formado por docentes e supervisoras pedagógicas, foi constituído a partir do trabalho realizado. O grupo propôs

\footnotetext{
14 Grupo formado por dezesseis representantes do corpo docente da escola, sendo doze professoras(es), três supervisoras pedagógicas e a diretora. Esse grupo ficou responsável por estudar o material dos Indiques e auxiliar o Núcleo na organização da autoavaliação participativa.
} 
reformulações em planos de aula para contemplar a abordagem de conteúdos relacionados às relações étnico-raciais.

A etapa final consistiu na realização de grupos focais, os quais contaram com a participação de graduandas do Curso de Psicologia da Universidade Pontifícia Católica (PUC-Minas). Com a técnica de Grupo Focal, buscou-se entender como o processo de construção identitária étnicoracial tem sido concebido pelos(as) jovens estudantes negros(as) no contexto escolar e fora dele e quais fatores os(as) afetam ${ }^{15}$. Gatti (2012) considera que o uso do recurso metodológico do Grupo Focal possibilita aprofundar questões para serem debatidas entre os próprios integrantes.

Foram formados dois grupos em cada turno. Realizamos duas reuniões com duração de 75 minutos com cada grupo, todas elas foram filmadas e posteriormente os relatos foram transcritos. A composição dos grupos contou com a maioria do sexo feminino e entre sete e oito discentes em cada. A mediação deles foi conduzida por três graduandas do décimo período de Psicologia e dois estudantes do Núcleo, que atuaram como observadores.

No espaço dos grupos, foram discutidos temas importantes, como racismo no espaço escolar, discriminação da mulher negra, genocídio da juventude negra, racismo estrutural e institucional, cotas raciais, desigualdades étnico-raciais no mercado de trabalho, entre outros.

Os resultados do estudo alcançados apontam que a constituição identitária étnico-racial desses sujeitos se revela em meio à vivência de uma trajetória marcada pelo racismo, preconceito e discriminação racial. Essa preocupante constatação implica a necessidade de investir em práticas educativas voltadas para a promoção da igualdade étnico-racial no ambiente escolar.

\footnotetext{
${ }^{15}$ As principais questões que nortearam os diálogos ocorridos foram: Você já presenciou alguma situação de racismo ou discriminação racial tanto na escola quanto fora dela? Você já foi vítima de racismo ou discriminação racial? Você acredita que atitudes racistas podem afetar a trajetória escolar do(a) estudante negro(a)? De que forma?
} 
Partindo dessa perspectiva, é possível entender que as tensões, as desigualdades e os conflitos sociorraciais verificados na sociedade são também reproduzidos e produzidos na/pela escola, pois, afinal:

A escola não é um campo neutro onde, após entrarmos, os conflitos sociais e raciais permanecem do lado de fora. A escola é um espaço sociocultural onde convivem os conflitos e as contradições. O racismo, a discriminação racial e de gênero, que fazem parte da cultura e da estrutura da sociedade brasileira, estão presentes nas relações entre educadores/as e educandos/as (GOMES, 1996, p. $69)$.

Educar para a promoção da igualdade étnico-racial só é possível, portanto, na medida em que a formação da pessoa humana, de maneira mais abrangente, é considerada central no desenvolvimento das práticas escolares. Significa considerar que os processos de ensino-aprendizagem ocorrem para além da escolarização das juventudes (DAYRELL, 2007; SILVA, 2019a; SPÓSITO, 1999).

\section{Educação das Relações Étnico-Raciais no ensino médio: pelo direito à autonomia intelectual e do pensamento crítico}

É notório o entendimento de que uma das funções da educação básica brasileira diz respeito a assegurar a formação dos estudantes para o exercício da cidadania. No que concerne ao ensino médio, que é considerado etapa final, o inciso III, do artigo 35, contido na LDBEN $n^{\circ}$ 9.394/96, explicita as finalidades desse nível de ensino: "o aprimoramento do educando como pessoa humana, incluindo a formação ética e o desenvolvimento da autonomia intelectual e do pensamento crítico" (BRASIL, 1996, p. 13). 
Se a formação ética e o aprimoramento intelectual do pensar crítico são alguns dos pressupostos contemplados nesse dispositivo jurídiconormativo legal, por que é tão difícil tratar as questões étnico-raciais no ambiente da educação escolar? Sabemos as diferenças existentes entre o caráter prescrito previsto em Lei e a sua operacionalidade na vida prática cotidiana das pessoas. Contudo, em se tratando de compreender a abordagem das relações étnico-raciais na escola, uma breve revisão histórica revela que a conquista do direito à educação aconteceu por meio de lutas por parte da população negra (GONÇALVES; SILVA, 2000; SILVA, 2019b; PAIXÃO, 2014).

A naturalização do preconceito e da discriminação racial, a crença da existência da vida democrática sem a existência de conflitos sociorraciais e a exaltação acrítica da mestiçagem perpetuam o racismo à brasileira. No entendimento de Kabengele Munanga (2010, p. 453), a tentativa histórica de construção de uma identidade coletiva nacional mestiça, deliberadamente imposta pelas elites dominantes, deveria ser nomeada como "racismo assimilacionista".

Se, de um lado, a expectativa da miscigenação brasileira é discriminatória porque espera que os negros clareiem em vez de aceitá-los tal qual são, de outro ela é integradora como mecanismo de miscigenação.

Ao propormos discutir como os estudantes lidam com o processo de constituição identitária étnico-racial, o tema sobre a mestiçagem é praticamente incontornável. Todavia, as suas falas fazem emergir experiências sociorraciais conflitivas vivenciadas no percurso escolar no sentido de constituir uma identidade negra positivada.

Eu já tentei me matar, já tentei muita coisa porque é ruim você chegar em sala de aula e a maioria dos colegas chegar e achar que 
é você é qualquer uma. Eu tenho muita dificuldade. As pessoas me veem como se eu fosse bicho. O I. [colega de turma, também negro] está de prova. Na sala só tem nós dois de negros. As pessoas acham natural tudo que a gente fala eles riem (T. jovem negra, estudante do terceiro ano, turno matutino).

O conflito racial vivido pela estudante é elucidativo para descontruir a inexistência dos conflitos sociorraciais no interior da escola. O seu discurso é revelador no sentido de expor uma tentativa de tirar a sua própria vida, tendo em vista a agressão racial simbólica sofrida cotidianamente. Tudo isso se manifesta aparentemente do ponto de vista dos agressores(as) em tom de brincadeira. Sabe-se lá ante à presença de profissionais da educação. Afinal, se a educação para as relações étnico-raciais não é problematizada, por mais que faça parte dos marcos normativos legais, a prática do racismo, infelizmente, se perpetua no contexto escolar.

A jovem identifica a si própria e ao seu colega como sendo negra e negro. Esse reconhecimento identitário, que é ao mesmo tempo individual e coletivo, ocasiona o sentimento de pertença e de valorização da sua autoestima africana e afro-brasileira. Portanto, o entendimento de identidade tratada no estudo se aproxima do sentido antropológico dado ao termo:

A identidade é um princípio de coesão interiorizado por uma pessoa ou um grupo. Permite-lhes reconhecerem-se e serem reconhecidos. A identidade consiste num conjunto de características partilhadas pelos membros do grupo, que permitem um processo de identificação das pessoas no interior do grupo e de diferenciação em relação aos outros grupos. A identidade nunca está definida de uma vez por todas. É um processo de inclusão no interior e de exclusão no exterior (LABURTHE-TOLRA; WARNIER, 1997, p. 409). 
O processo de construção da identidade negra, individual e coletiva, se relaciona, portanto, com "uma proposta política de construir a solidariedade e identidade dos excluídos pelo racismo à brasileira" (MUNANGA, 2006, p. 53). Esse autor destaca ainda o protagonismo exercido pelo Movimento Negro em relação a criar condições solidárias, políticas, sociais e educativas, entre outros, em diferentes períodos históricos, para a população negra brasileira.

Foi no âmbito de realização das atividades do NUPEAAs que muitos(as) dos(as) profissionais da educação envolvidos(as) com o projeto tomaram conhecimento dos conflitos sociorraciais enfrentados pelos(as) estudantes negros(as) pesquisadores(as) relacionados(as) ao processo de constituição identitária negra.

Os estudantes descreveram inúmeras situações de práticas discriminatórias vividas em suas trajetórias escolares. Eles(as) identificam o Ensino Fundamental I como o nível de ensino mais difícil de lidar com o preconceito e a discriminação racial. Entendem que não possuíam mais a ingenuidade de quando estavam na educação infantil e pré-escola. Reconhecem que lhes faltam condições sociopsíquicas adequadas para enfrentar os conflitos sociorraciais que ainda permanecem muito presentes no cotidiano escolar.

A construção da personalidade dos indivíduos é diretamente influenciada pelo contexto sociocultural. Assim sendo, a identidade negra dos jovens é concebida por meio de um movimento de negação-afirmaçãoreafirmação no interior das relações sociorraciais. O drama sociopsíquico do preconceito e da discriminação racial por eles(as) vivenciado ocorre por meio da "consciência de cor", descrita por Virginia Bicudo (2010, p. 165), como parte resultante das assimetrias sociais entre negros e brancos a partir do entrelaçamento das dimensões de classe, raça e gênero, perpassado pelo ideal de branqueamento. 
Vivendo o conflito entre ser "negro" e "não querer ser negro", equivalente ao conflito entre "ser mau" e "ser bom", as pessoas de cor sucumbem frequentemente ao conflito, autopunitivamente exibindo traços de personalidade que são tomados como confirmação dos estereótipos que lhe são dirigidos. Outros derivam o conflito na luta pela aquisição de características de branco procurando instruir-se, elevar seu status.

O estudo realizado apontou que a constituição da identidade negra dos sujeitos com os quais dialogamos acontece por meio do conflito sociorracial. Com as atividades desenvolvidas no Núcleo, consideramos que a instituição escolar, nesse caso, exerce uma função social importante no sentido de promover o respeito, o reconhecimento e a valorização da cultura africana e afro-brasileira.

\section{Saber escolar e a diversidade étnico-racial}

A realização da pesquisa e as intervenções políticas, artísticas e educativas em torno das relações étnico-raciais propostas pelos integrantes do Núcleo foram capazes de interferir de maneira positiva e reflexiva no cotidiano escolar.

Buscar conhecer e valorizar as trajetórias estudantis dos(as) jovens negros(as) de certa forma levou a comunidade escolar a repensar sobre o saber da cultura escolar até então predominante. Em outras palavras, até aquele momento, os poucos trabalhos desenvolvidos voltados para a promoção da igualdade racial ocorreu de modo pontual e pouco sistematizado. Porém, com a realização do UBUNTU/NUPEAAs, pôde-se perceber o envolvimento e a participação comunitária em torno dessa temática de maneira planejada, coletiva e colaborativa.

Garantir centralidade à realidade social e psicológica desses sujeitos desafia-nos a ampliar a compreensão a respeito da noção de cultura escolar. 
Desse modo, para além dos objetivos normativos que são ali estabelecidos, a cultura escolar é constituída por complexas relações sociais que se manifestam a partir do processo de interação intersubjetiva entre pessoas humanas.

E, nesse caso, a aproximação das práticas escolares com o intuito de perceber as trajetórias e vivências estudantis em relação às experiências das relações étnico-raciais que interferem no processo de constituição identitária desses sujeitos "não se trata, simplesmente, de caracterizar os protagonistas que atuam no espaço escolar e relacioná-los às condições sociais, políticas e econômicas (...) o que interessa é descrever as 'práticas escolares' e os seus correlatos (objetivados em mentalidades, conflitos, discursos, procedimentos, hábitos, atitudes, etc.)" (AZANHA, 1991, p. 66-7).

Tomar conhecimento de práticas discriminatórias raciais ocorridas no ambiente escolar, como revela o depoimento de uma jovem estudante negra, "tenho dificuldades de aprendizagem na escola é que o meu melhor amigo me chama de feijão preto, porém eu não gosto, e já pedi várias vezes para ele parar [e não me chamar assim]" põe em relevo que o racismo se manifesta inclusive nas relações com forte vínculo socioafetivo, afinal, trata-se de seu melhor amigo.

O processo de desumanização da pessoa negra se constatou por meio de "zoação", "apelido" e "estereótipos" nas interações estabelecidas entre docente-discente e discente-discente. Assim, as práticas de discriminação racial se entrecruzam com as práticas escolares. A cultura escolar, nesse caso, contribui para a produção e reprodução da baixa autoestima, além de impedir que jovens negros(as) constituam uma identificação afirmativa étnico-racial.

Eu já sofri por professores. Foi na minha antiga escola, a gente estava fazendo um projeto lá e vinham pessoas de outro país conhecer a nossa escola. Aí os professores pediram pra gente ir todo arrumadinho. Foi quando eu fui com o meu cabelo solto. 
Tinha achado bem legal! Só que os professores começaram a me criticar, falando que eu estava envergonhando a escola. Não só os professores, mas também alguns colegas. Eu não consigo mais gostar de mim. Não tenho autoestima, nem confiança para deixar meu cabelo solto ou para mostrar para as pessoas a minha descendência. E eu acho que isso ainda me afeta hoje em dia (Le., jovem negra, estudante do segundo ano, turno matutino, participante do Grupo Focal).

Eu tinha o cabelo muito crespo, ele era "super armado"! Eu usava ele solto para ir para a escola. Muitas vezes eu usava preso por conta dos colegas que ficavam "zoando" meu cabelo. Eu comecei a passar prancha e com o tempo meu cabelo foi quebrando. Eu ainda passo prancha, porque eu me sinto bem. (I., jovem negra, estudante do primeiro ano, turno vespertino, participante do Grupo Focal).

Eu sempre via aquelas atrizes na TV, aquelas loiras, eu queria ser igual. Por mais que tivesse gente ali apoiando, parece que você estava sozinha, sabe? Teve até uma época aqui que eles "zoavam" muito meu cabelo. Diziam que o pente não passava e que ele não penteava o cabelo. Que o pente quebrava! Meu cabelo tinha escova progressiva, mas como meu cabelo é muito fino ele quebrava todo e começava a cair. Então, eu tive que cortar, ficou bem pequenininho, eu ficava com vergonha e usava touca. Eu saía na rua com aquele calor e eu estava com blusão, com touca, não tirava por nada. Comecei a usar peruca, mas aconteceu um "acidente" na escola, puxaram a minha peruca e eu não sabia lidar muito bem com meus problemas. (Li., jovem negra, estudante do primeiro ano, turno vespertino, participante do Grupo Focal).

A corporeidade negra e o cabelo crespo são identificados pelas jovens negras como os principais marcadores sociais e simbólicos de discriminação 
racial. De igual modo, numa interpretação crítica, esses mesmos marcadores têm sido historicamente ressignificados e constituídos como expressão política e identitária de afirmação da negritude.

Ideias como "arrumadinho", ter o cabelo "super armado" e "eu queria ser igual àquelas atrizes loiras" escamoteiam o ideal normativo de brancura social (RAMOS, 1995) imposto, inclusive, para uma parcela da população distinta fenotipicamente. A violência presente nesse processo ocasiona, entre outras coisas, o sentimento de inadequação, baixa autoestima e não identificação étnico-racial.

Nilma Gomes (2003) considera o cabelo e corpo como dimensões constituintes da formação identitária negra. Tomar conhecimento da violência e opressão vivenciada pelas estudantes, tendo em vista o corpo e o cabelo crespo, contribuiu para referendar a importância do trabalho desenvolvido pelo Núcleo, bem como o despertar determinado nível de consciência crítica a respeito da necessidade da abordagem da ERER na educação média.

Entender a importância da simbologia do corpo negro, a manipulação do cabelo e dos penteados usados pelos negros de hoje como formas de recriação e ressignificação cultural daquelas construídas pelos negros da diáspora poderá ser um bom tema de estudo e debate dentro da discussão sobre história e cultura afrobrasileira. Mas, para isso, será preciso que os educadores alterem suas lógicas escolares e conteudistas, dialoguem com outras áreas, valorizem a produção cultural negra constituída em outros espaços sociais e políticos (GOMES, 2003, 181).

Reeducar para as relações étnico-raciais, nesse caso, implica que o saber escolar se concretiza a partir de especificidades contextuais que estão intrinsecamente relacionadas ao tratamento histórico destinado às populações negras na sociedade brasileira "aliás, o que se passa na escola é apenas parte de um fenômeno muito mais amplo (...) a função central desse 
saber [escolar], que compõe essencialmente a cultura escolar (...) ele é sistematicamente ignorado ou nem mesmo percebido pela investigação educacional” (AZANHA, 1991, p. 68).

A concretização do saber e da cultura escolar relacionada com a diversidade étnico-racial está assentada, portanto, no projeto modernidadetardia-colonial, a qual se fundamenta em relações de poder-saber, que incidem na constituição intersubjetiva do ser negro.

Partindo dessa compreensão, ficou nítido para nós que conhecer trajetórias de estudantes negros(as) traz, como consequência, a necessidade de realização de outras e/ou novas práticas escolares que levem em consideração não só os efeitos das desigualdades sociorraciais na vida dos(as) jovens, como também busquem valorizar a história e a cultura afrobrasileira e africana.

A esse respeito, o Plano Nacional de Implementação das DCNERER estabelece como ações primordiais para esse nível de ensino:

a) Ampliar a oferta e a expansão do atendimento, possibilitando maior acesso dos jovens afrodescendentes ao ensino médio; b) Assegurar a formação inicial e continuada aos/às professores/as desse nível de ensino para a incorporação dos conteúdos da cultura afro-brasileira e indígena e o desenvolvimento de uma educação para as relações étnicoraciais; c) Contribuir para o desenvolvimento de práticas pedagógicas reflexivas, participativas e interdisciplinares, que possibilitem ao educando o entendimento de nossa estrutura social desigual; d) Implementar ações, inclusive dos próprios educandos, de pesquisa, desenvolvimento e aquisição de materiais didáticos diversos que respeitem, valorizem e promovam a diversidade cultural a fim de subsidiar práticas pedagógicas adequadas à educação para as relações étnico-raciais; e) Prover as bibliotecas e as salas de leitura de materiais didáticos e paradidáticos sobre a temática 
étnico-racial adequados à faixa etária e à região geográfica do jovem; f ) Distribuir e divulgar as Diretrizes Curriculares Nacionais para a Educação das Relações Étnico-Raciais e para o Ensino de História e Cultura Afro-Brasileira e Africana entre as escolas que possuem educação em nível médio, para que as mesmas incluam em todos os componentes curriculares os conteúdos que versam sobre essa temática; g) Incluir a temática de história e cultura africana, afro-brasileira e indígena entre os conteúdos avaliados pelo ENEM; h) Inserir a temática da Educação das Relações Étnico-Raciais na pauta das reuniões do Fórum dos/as Coordenadores/as do Ensino Médio, assim como manter grupo de discussão sobre a temática no Fórum Virtual dos/as Coordenadores/as do Ensino Médio; i) Incluir, nas ações de revisão dos currículos, a discussão da questão racial e da história e cultura africana, afro-brasileira e indígena como parte integrante da matriz curricular (BRASIL, 2009, p. 51-2, grifos nossos).

Reinventar o currículo parece o termo adequado levando em consideração o atual contexto local-global, em que pessoas e povos lutam por reconhecer e valorizar as suas diversidades. Desnaturalizar camadas de opressões e violências simbólicas, materiais e epistêmicas secularmente transmitidas pelas instituições de ensino se torna cada vez mais necessária.

Afinal, "por um efeito de desconhecimento estrutural próprio de todo empreendimento de transmissão simbólica, aquilo que pode haver de contingente, de arbitrário, de socialmente construído ou ideologicamente enviesado nos conteúdos de ensino, está destinado a permanecer despercebido; a naturalização da coisa ensinada" (FORQUIN, 1992, p. 43).

A criação do NUPEAAs na escola consistiu no desafio de problematizar "valores universais" expressos nos conteúdos de ensino e nas práticas escolares fazendo com que buscássemos construir um saber teórico e escolar fundamentado na educação das relações étnico-raciais com vistas a 
(re)conhecer, respeitar e valorizar a trajetória escolar e de vida de sujeitos negros e negras.

FIGURA 1: Encerramento do Projeto - Festival UBUNTU



Fonte: Arquivo de Pesquisa.

\section{Considerações Finais}

O estudo revelou que o processo de constituição da identidade negra de jovens estudantes se manifesta a partir da vivência de práticas discriminatórias raciais em suas trajetórias sociais e escolares. Essa constatação é preocupante devido ao fato de eles se depararem com o sentimento de inadequação, baixa autoestima e não identificação étnicoracial.

Constatamos ainda que a concretização desse tipo de violência sociorracial apresenta um caráter simbólico, material e epistêmico, o qual tem sido problematizado de maneira bastante incipiente nas práticas escolares observadas (planos de aula, interações, livros didáticos, etc.).

Assim sendo, a presença considerável de jovens negros(as) inseridos(as) no ensino médio não tem sido capaz de modificar a secular 
cultura escolar hegemônica, que se diz fundamentada em "valores universais" da humanidade.

Com o estudo realizado, foi possível entender que a realidade social e psicológica desses sujeitos desafia ampliar essa noção de cultura escolar. Logo, para além do seu caráter normativo, a cultura escolar é constituída por complexas relações sociais que se explicitam a partir do processo de interação intersubjetiva entre pessoas humanas.

Daí a importância das ações desenvolvidas pelo NUPEAAs que, a partir de um trabalho coletivo, buscou promover uma educação das relações étnico-raciais baseada na valorização da história e cultura afro-brasileira e africana.

Por conseguinte, os novos conhecimentos adquiridos nos possibilitaram refletir e realizar práticas educativas, contando com a efetiva participação dos(as) jovens negros(as) e brancos(as) a partir da construção de um plano de ação escolar com vistas a promover a valorização da diversidade étnico-racial.

Consideramos, por fim, que conhecer trajetórias de estudantes negros(as) contribuiu para promover transformações de histórias de vida.

\section{Referências}

ARAÚJO, Jurandir A. Educação e Desigualdade: a conjuntura atual do ensino público no Brasil. Revista Direitos Humanos e Democracia. Editora Unijuí, ano 2, n. 3, jan./jun., 2014. Disponível em: $<$ https://www.revistas.unijui.edu.br/index.php/direitoshumanosedemocracia>. Acessado em: 05 jun. 2019.

AZANHA, José M.. Cultura escolar brasileira: um programa de pesquisas. São Paulo: Revista USP, n. 8, p. 65-69, 28 fev. 1991. Disponível em: <http://www.revistas.usp.br/revusp/article/view/52136> Acesso em: 08 mar. 2019.

BICUDO, Virgínia L. Atitudes raciais de pretos e mulatos em São Paulo. Edição organizada por MAIO, Marcos. São Paulo: Editora Sociologia e Política, 2010.

BRASIL. Lei $n^{\circ}$. 9.394, de 20 de dezembro de 1996. Estabelece as diretrizes e bases da educação nacional. Diário Oficial da União, 23 dez. 1996. Disponível em: <www.planalto.gov.br/ccivil_03/LEIS/19394.htm>. Acesso em: 27 ago. 2015. 
BRASIL. Lei $n^{\circ}$. 10.639, de 9 de janeiro de 2003. Altera a Lei n. 9.394, de 20 de dezembro de 1996, que estabelece as diretrizes e bases da educação nacional, para incluir no currículo oficial da Rede de Ensino a obrigatoriedade da temática "História e Cultura Afro-Brasileira", e dá outras providências. Diário Oficial da União, $\quad 1^{\circ} \quad$ jan. $2003 . \quad$ Disponível em: <http://www.planalto.gov.br/ccivil_03/leis/2003/110.639.htm>. Acesso em: 13 jun. 2016.

BRASIL. Lei $n^{\circ}$. 11.645, de 10 de março de 2008. Altera a Lei $n^{\circ} .9 .394$, de 20 de dezembro de 1996, modificada pela Lei no 10.639, de 9 de janeiro de 2003, que estabelece as diretrizes e bases da educação nacional, para incluir no currículo oficial da rede de ensino a obrigatoriedade da temática "História e Cultura AfroBrasileira e Indígena", e dá outras providências. Diário Oficial da União, 25 março. 2008. Disponível em: <www.planalto.gov.br/ccivil_03/_ato20072010/2008/lei/111645.htm>. Acesso em: 25 jun. 2015.

BRASIL. Ministério da Educação Conselho Nacional de Educação. Diretrizes curriculares nacionais para a educação das relações étnico-raciais e para o ensino de História e Cultura Afro-brasileira e Africana. Brasília: Ministério da Educação, 2004. Disponível em: <http://portal.inep.gov.br/informacao-da-publicacao//asset_publisher/6JYIsGMAMkW1/document/id/488171>. Acesso em: 20 nov. 2017.

BRASIL. Plano de implantação das diretrizes curriculares nacionais para a educação das relações étnico-raciais e para o ensino de História e Cultura Afrobrasileira e Africana. Brasília: Ministério da Educação \& Secretaria Especial de Políticas de Promoção da Igualdade Racial, 2009. Disponível em: <portal.mec.gov.br/docman/fevereiro-2012-pdf/10098-diretrizes-curriculares>. Acesso em: 13 set. 2017.

CARREIRA, Denise; SOUZA, Ana Lúcia Silva. Indicadores da qualidade na educação: relações raciais na escola. São Paulo: Ação Educativa, 2013.

CARVALHO, Isabela Bastos de; CASTRO, Alexandre de Carvalho. Currículo, Racismo e o ensino de Língua Portuguesa: as relações étnico-raciais na educação e na sociedade. Educ. Soc., Campinas, v. 38, n. 138, p. 133-151, jan., 2017. Disponível em: <http://www.scielo.br/scielo.php?script=sci_arttext\&pid=S0101$73302017000100133 \& \operatorname{lng}=e n \& n r m=i s o>$. Acessado em: 05 jun. 2019.

CUNHA, Andréia M. et al. Articulação entre iniciação científica e promoção da igualdade racial no ensino médio: uma estratégia para políticas públicas educacionais. Revista da Associação Brasileira de Pesquisadores/as Negros/as (ABPN), [S.l.], v. 10, p. 230-242, jan. 2018. Disponível em: <http://www.abpnrevista.org.br/revista>. Acesso em: 15 set. 2018.

DAYRELL, Juarez. O jovem como sujeito social. In: SPÓSITO, M; CARRANO, P.; FÁVERO, O; NOVAES, R. (Orgs.). Juventude e Contemporaneidade. Brasília: UNESCO/MEC/ANPEd, 2007. p 155-178. Disponível em: <portal.mec.gov.br/docman/documentos-pdf/648-vol16juvcont-elet-pdf>. Acessado em: 05 fev. 2017. 
FORQUIN, Jean-Claude. Saberes escolares, imperativos didáticos e dinâmicas sociais. Teoria \& Educação, Porto Alegre, Pannonica, v. 1, n. 5, p. 28-49, 1992. Disponível em: <https://edisciplinas.usp.br/mod/resource/view.php?id=938687>. Acesso em: 29 jun. 2018.

GATTI, Bernadete Angelina. Grupo focal na pesquisa em ciências sociais e humanas. Brasília: Líber Livro, 2012.

GOMES, Nilma Lino. Educação, identidade negra e formação de professores/as: um olhar sobre o corpo negro e o cabelo crespo. Educação e Pesquisa, São Paulo, v.29, n.1, p. 167-182, jan./jun. 2003. Disponível em: $<$ http://www.scielo.br/scielo.php?pid=S1517-

97022003000100012\&script=sci_abstract\&tlng=pt>. Acesso em: 29 jun. 2018.

Educação, raça e gênero: relações imersas na alteridade. Cadernos Pagu: raça e gênero, Campinas: Unicamp, v. 6-7, p. 67-82, 1996. Disponível em: $<$ https://periodicos.sbu.unicamp.br/ojs/index.php/cadpagu/article/view/1862>.

Acesso em: 13 mar. 2018.

GONCALVES, Luiz Alberto Oliveira; SILVA, Petronilha Beatriz Gonçalves e. Movimento negro e educação. Rev. Bras. Educ., Rio de Janeiro, n. 15, p. 134-158, Dec. 2000. Disponível em: $<$ http://www.scielo.br/scielo.php?script=sci_arttext\&pid=S1413-

$24782000000300009 \& l n g=e n \& n r m=i s o>$. Acesso em: 20 jan. 2015.

GUIMARÃES, Antônio S.. Como trabalhar com "raça" em sociologia. Educação e Pesquisa, São Paulo, v.29, n.1, p. 93-107, jan./jun. 2003. Disponível em: $<$ http://www.scielo.br/scielo.php?pid=S1517-

97022003000100008\&script=sci_abstract\&tlng=pt>. Acesso em: 27 mar. 2017.

IBGE. Pesquisa Anual por Amostra de Domicílios Continua (PNAD-Contínua) 2018. Disponível em: <https://agenciadenoticias.ibge.gov.br/agencia-sala-deimprensa/2013-agencia-de-noticias/releases/24857-pnad-continua-2018-educacaoavanca-no-pais-mas-desigualdades-raciais-e-por-regiao-persistem $>$. Acessado em: 09 jul. 2019.

LABURTHE-TOLRA, Philippe; WARNIER, Jean-Pierre. Etnologia-Antropologia. Trad. Anna Cavalcanti. Petrópolis, RJ: Vozes, 1997.

MUNANGA, Kabengele. Algumas considerações sobre "raça", ações afirmativas e identidade negra no Brasil: fundamentos antropológicos. Revista USP, São Paulo, n.68, p. 46-57, dez.-fev., 2006. Disponível em: $<$ http://www.revistas.usp.br/revusp/article/view/13482>. Acessado em: 15 jul. 2017.

Mestiçagem como símbolo da identidade brasileira. In. SANTOS, B.; MENESES, M. (Orgs.). Epistemologias do Sul. SP: Cortez, 2010. p. 444-454.

PAIXÃO, Marcelo. A lenda da modernidade encantada: por uma crítica ao pensamento social brasileiro sobre relações raciais e projeto de Estado-Nação. Curitiba, PR: CRV, 2014. 
RAMOS, Alberto Guerreiro. Introdução crítica à sociologia brasileira. Rio de Janeiro: Editora UFRJ, 1995.

SILVA, N. V.; HASENBALG, C. Tendências da desigualdade educacional no Brasil. Dados, Rio de Janeiro, vol. 43, n. 3, 2000. Disponível em: $<$ http://www.scielo.br/scielo.php?pid=S0011-

52582000000300001\&script=sci_abstract\&tlng=pt>. Acessado em: 10 jun. 2015.

SILVA, Natalino Neves da. Qual é o valor do ensino médio? Experiência social e escolar de jovens negros(as) e brancos(as). Curitiba: Appris, 2019a.

SILVA, Petronilha Beatriz Gonçalves e. Raça Negra e Educação 30 anos depois: memórias e legados. Revista da Associação Brasileira de Pesquisadores/as Negros/as (ABPN), v. 11, n. Ed. Especi, p. 12-31, abr. 2019b. Disponível em: $<$ http://www.abpnrevista.org.br/revista/index.php/revistaabpn1/article/view/679>. Acesso em: 12 jul. 2019.

SPÓSITO, Marília Pontes. Educação e juventude. Educação em Revista, Belo Horizonte, n.29, p. 7-13, jun. 1999. Disponível em: $<$ http://educacaoemrevistaufmg.com.br/edio-anterior/educacao-em-revista-no-29ano-1999/>. Acesso em: 21 mar. 2015. 